\title{
MEDICAL INSPECTION IN ENGLISH PRIMARY SCHOOLS
}

\author{
HERBERT LEATHER \\ Manchester, England
}

Portents are not lacking which augur a complete revolution of the system which governs the primary schools of England.

When the industrial revolution of the eighteenth century hurled down the ancient supremacy of the manual crafts, reducing the sturdy workers of England to dependence upon the whirling machinery of the factory or workshop their position was analogous to that of a man who enters life with capital intact. The markets of the world were open to their products; the physical capacity of the workers to produce was boundless; work was plentiful. Yeoman farmers, no longer able to coax subsistence from the soil, sold their holdings and rushed to the centers of industry; the fishermen of Cornwall and Devon with their families flocked to the towns of Lancashire and Yorkshire where work at fabulous wages could be secured in abundance. Even the children could earn, untrammeled by inconvenient restrictions; and the nation spent recklessly of its inherited physical capital.

Then followed that period of commercial expansion the like of which has only been equaled in the development of the New World. The desolate wastes of the North became busy hives of industry; first the factory, then the houses, then the towns.

Coal fields, iron foundries, ship-building yards sprang up as though by magic; canals, new roads, and railways quickly connected the various centers, so that whole districts became in effect large towns. Fortunes were made freely, and if lives were lost among the busy wheels of industrial strife, if the young and helpless went down, if the workers began to age prematurely and to become marked with the deep-scored lines which stamp an impress upon the third and fourth generations, what mattered 
it so long as fresh supplies of bone and muscle rushed eagerly in from the country?

When improved methods of work were required there sprang up a demand for education which resulted in the passage of the act of 1870. That the perspective of its framers was limited almost solely to the training of the mind, ignoring the problem of physical development, was unfortunate; that the stage of mental development should be assessed and paid for, after the manner of the buyer in a great cotton or woolen concern, was a calamity the consequences of which are yet being bitterly felt.

Despite high rates of wages and the wider knowledge of healthy conditions of living which prevail today as compared with those of yesterday nearly all the great centers of population are faced with the presence of large numbers of unemployable men. While the workhouses are full, 5 per cent. of the present population being paupers, lunacy is increasing at an appalling rate. The terrible effects of town life are illustrated by the significant fact that the percentage of pauperism in London exceeds seven; and that such things should be in face of the enormous number of charitable organizations which are actively at work indicates the gravity of the problem which confronts the English nation.

Of the various social questions having for their object the elimination of physical deterioration the educationist is naturally chiefly interested in those which concern the welfare of the child.

Since the abolition of the system of payment by results, increasing attention has been paid by the Board of Education to the policy of improving the physical development of school children, especially in recent years. Provision must now be made in all school time-tables for a recreation interval during morning and afternoon sessions; in infant schools this interval may be prolonged, and lessons in all departments must be so arranged as to avoid any risk of undue fatigue in the pupils.

For very many years an elaborate system of military drill was encouraged in the schools, and this has recently been elaborated into a scheme more consonant with modern ideas of physical development. Every primary-school pupil is now taught to 
breathe correctly, and, if the existing scheme be persisted in, there should in time be a considerable diminution in the number of mouth-breathing children.

The inspectors of the Board have effected vast changes in the structural arrangements of schools by means of recommendations to managers in their annual reports; many schools which are condemned today would have been regarded as thoroughly satisfactory only a few years ago.

The splendid work of the inspectors in this department has been so gradually wrought that it is frequently overlooked altogether by prominent educationists. Not only is the practical hygiene of the school strictly supervised, but courses of wellgraded instruction in personal hygiene are organized for the benefit of the pupils in attendance. There is, too, the provision in the Primary-School Code which sanctions gardening as an ordinary subject of the curriculum, and one which is being widely taken up in suburban and rural schools. Outdoor teaching is also sanctioned when suitable schemes are submitted by teachers, in all schools. The Board's encouragement of outdoor teaching has recently been extended by the inclusion of organized games in the general curriculum. The teaching of special subjects, as manual work for boys, and cookery and laundry work for girls, is also recognized by the Board by the payment of specia! grants.

It would appear therefore that the policy of the Board of Education, as distinct from that of the general government, is strongly in favor of securing sound physical development among the children in so far as this may be secured without interfering with the purely educational work of the schools-vide Suggestions to Educationists: "The duty of safeguarding the health of children of school age is only in a limited degree a duty of the school."

Had the present policy of the Board been inaugurated with the introduction of the industrial revolution it is possible that the problem of physical degeneracy would not have arisen in its present urgent form. The terrible tales told by the recruiting returns of disease and low vitality, in conjunction with a steady and alarming decrease in the national birth rate, have caused 
serious disquiet among all active workers on public administrative bodies. Earnest educationists have brought forward the whole question as it concerns the rising generation. "Begin with the child," they argue; "once given a fair start he will attain sound physical development and perform his share in the world's work."

In the last annual report of the London Education Committee it was pointed out that a process of selection had been introduced by the establishment of special schools for defective children. The process was carried out under the supervision of skilled medical advice and for the first time there was systematic medical inspection of a section of primary-school children. In order adequately to assess the value of the special work of schools, a medical specialist was appointed by the Board of Education. It was soon ascertained that children classed as defective were of many types; there were those so closely related to idiocy that while they could derive no benefit from the ordinary curriculum of special schools they greatly impeded the progress of those who could. For such cases the policy of permanent segregation under healthy conditions is being actively advocated. Other defectives were discovered to be of the epileptic class, and for these also separate schools are advised. Mental defect was often found to be the result of parental neglect or ignorance, and after simple surgical treatment was administered the defect gradually disappeared.

When medical officers were more generally appointed by the progressive educational areas for the purpose of inspecting cases for special schools it was discovered that the physical condition of school children throughout the country was marked in many respects by grave weakness; and in order that all the children under their control might be subjected to medical examination, additional doctors were appointed. As a result it became a statutory obligation on education committees to provide medical inspection for all children, on and after January I, I908. Many education committees as yet have not decided to take up the question thoroughly on grounds of expense, although children who suffer from grave defects of sight and hearing, if neglected, 
usually develop into the unemployable men and women whose ultimate destination is the poorhouse; so that the cost of initial neglect falls very heavily upon the general community.

It may prove interesting to record the experience of some of the pioneer education authorities in the field of medical inspection of school children.

One of the most comprehensive schemes is that drawn up by the committee of the Govan School Board. Ten medical officers are employed and the average number of children under the charge of each is about 3,00o. The duties of officers are to advise the Board as to the ventilation, heating, lighting, and cleanliness of the schools; to inspect periodically all school lavatories and sanitary arrangements and to report to the headmaster any defects discovered; on receiving notice of an outbreak of infectious disease among the pupils attending any school the officers are to inquire and take such action as may be necessary to prevent infection, for which purpose they must co-operate with the Medical Officer of Health for the district; special schools and classes are to be reported on twice a year and the officers are to give the necessary certificates of admission to defective children seeking entry to such schools. They are to examine all scholars on admission and twice thereafter during their school life, and for the purpose of these examinations the schools are to be visited as cften as may be necessary, but at least once a fortnight; they are to make reports on children submitted for examination by headmasters and to give such directions as may be required; they are to supervise such systematic measurements of heights and weights as the Board shall approve, inspect the physical exercises given in the schools, and medically examine candidates appointed to positions under the Board; finally they are by lecture, demonstration, or otherwise to instruct teachers in the methods of recognizing the common ailments and defects of school children, in the practice of first aid for school accidents, in the general hygiene of the school, and in the physiological principles that underlie physical training.

The teachers render assistance to the medical officers in filling up those parts of the Health Schedule, one of which is filled up 
for each child examined, relating to height, weight, chest measurement, etc. When a child is found to be suffering from any disease or defect, the medical officer informs the parent of the nature of the malady and urges upon him the necessity of placing the child under the care of a doctor. Medical or surgical treatment is no part of the medical officer's duty.

Although the School Board of Glasgow has not yet made arrangements for the medical inspection of all the children attending its schools the services of four special doctors have been employed for (I) testing the eyesight of the children, (2) examining scholars for admission to special schools, (3) examining the blind and the deaf mutes, (4) examining scholars for admission to physically defective classes, and for visiting and reporting on children who are absent from school on account of illness.

Under the supervision of Dr. Wright Thomson the eyesight of 52,493 children was recently tested, of whom 18,565 or 35 per cent. were found to be below the normal standard, and I I,209 or 2 I per cent. had ocular defects. The proportion of these cases was highest in the poor and closely built districts and in old schools, and was lowest in the better-class schools and in those near the city outskirts. Dr. Thomson points out that defective vision, apart from ocular defect, seems to be due to want of training of the eyes for distant objects and partly to exhatustion of the eyes induced by working in a bad light. $\mathrm{He}$ strongly advises teachers to train the eyes of children for long vision by the introduction of competitive games involving the recognition of small objects at a distance of 20 feet or more.

The Manchester Education Committee has for many years taken an active interest in the treatment of backward and defective children. In addition to several special schools staffed by teachers possessing the highest educational qualifications, a residential school for cripples has been established in a spacious mansion surrounded by wide stretches of well-wooded country at Swinton. Here the children are nursed back to health, and during the process they receive instruction under ideal conditions. 
On suitable days the pupils are taught on the lawn or in the shady spots which abound.

Mention must also be made of the summer school worked by the same authority. This institution is situated at Mobberley in the open country; and during the spring, summer, and autumn months, boys and girls from Manchester schools visit the country for a fortnight in charge of their teacher. Instruction of a suitable nature is given and there are long walks into the surrounding country. The parents of the visiting scholars contribute toward the expense of the visit and the success of the experiment has been so pronounced that the country school is now regarded as a permanent educational asset.

Quite recently several additional medical officers have been appointed to Manchester schools and the work of medical inspection is about to be organized upon a thoroughly comprehensive plan. Many of the more serious cases of mental defect and epilepsy in Manchester are transferred to the permanent home for the feeble-minded at Warford Hall, and the David Lewis Colony for Epileptics.

In Liverpool where the work of medical inspection is in the experimental stage there are three doctors for $\mathrm{I} 33,000$ children at the present time, but only children recently admitted, those about to leave school, and special cases are medically examined.

The Birmingham authorities have appointed three doctors with nurses to assist in the weighing, measuring, etc., of the children. There is a thorough medical examination with a high standard, equal to that adopted by the best insurance companies. A file index of all cases requiring supervision is kept for reference.

The splendid work done by Dr. James Kerr and his colleagues in the London County Council schools is only slightly indicated in the last report ${ }^{1}$ which is worthy of deep study from every educationist. In clear statistical form, the various ills from which school children suffer are set forth. For example it was discovered that only 20 of 700 infants examined had sound teeth;

${ }^{1}$ London County Council, Minutes of Proceedings (No. 33), December, I908. London: P. S. King \& Son, Gt. Smith St., Westminster, S. W. \$0.06. 
in two secondary schools 62 per cent. of the pupils had two or more defective teeth, and in the training colleges 43 per cent. were returned as having dental defects. The urgency of prompt remedial treatment is illustrated by the statement that if the dental cases alone were taken in hand all the hospitals in London could not provide for one-tenth of the afflicted children, and a similar lack of accommodation is shown for the treatment of eye and ear defects. For absence from school attendance through ringworm alone, $\mathfrak{t}_{5}, 6_{50}$ is lost annually in grants.

The whole report was submitted to a special subcommittee for further consideration with the result that the London County Council Education Committee has now recommended the establishment of school clinics where common diseases of the eye, ear, teeth, and skin may receive immediate medical treatment; and convenient centers are about to be erected.

In this respect London has given a notable lead to the rest of the country, for the introduction of school elinics can scarcely fail to mark an epoch in educational progress. For in England, after generations of aimless wandering in the wilderness of social and industrial conflict, it would appear at last to be clearly established that all national progress and educational vitality are dependent upon the physical fitness of the nation's children. 